\title{
THE ROLE OF THE REAL READER IN THE WRITING PROCESS
}

\author{
DIANA WEGNER \\ DOUGLAS COLLEGE, NEW WESTMINSTER, B.C.
}

Conventional writing pedagogy still includes the recitation of a litany of demographic factors deemed necessary for a satisfactory analysis of the writer's audience. Such pedagogy instructs students to consider educational level, age, and cultural background as important guidelines for making rhetorical and editorial decisions. But this classroom discussion is inevitably carried out in response to a grey and faceless concept of the reader. Texts and handbooks also reinforce this depiction of an abstract audience--of readers who are constituted as statistical and passive entities.

Generally these texts provide the standard classification of primary versus secondary readers, and a series of questions the writer must ask herself about her readers. In the texts I looked at there is no suggestion that writers might also consult the readers themselves. John Lannon's text, Technical Writing (1985), is typical in this respect. He counsels writers to "identify the primary readers by name, job title, and specialty," and to ask themselves, "Are they inside or outside your organization? Are they apt to agree or disagree with your conclusions and recommendations? Will your report be taken as good or bad news?" (16). Student-writers are thus instructed to guess at their audience's needs and reactions. In Writing That Works (Oliu, Brusaw, and Alfred; 1984) the authors advise, "Imagine yourself in your reader's position" (7); and in The Writer's Rhetoric and Handbook, a text geared for both academic and non-academic writing, McMahan and Day (1984) say of the audience: "Who are they? Well, you really have to imagine them, using your experience of people and the world" (200). 
In my examination of the role of the real reader, I hope to strengthen the critique of these misconceptions of the reader/writer relationship and to lend some support to proponents of the social context approach.

I will retum to the problems of pedagogy, but first I shall describe those elements of my study that suggested a different depiction of readers and texts. I studied the writing process of six reports, each at a different organization. All six were developed in a dynamic, collaborative context. By "collaborative" I am here referring to a broad phenomenon that includes both oral and written input from both readers and writers, in the form of commentary (agreements and disagreements) and in the form of additions and modifications to a written draft. The collaborative activities of my informants included meetings (formal and informal, over lunch and in the board room), workshops interviews, telephone conversations, visits to client organizations and other external sites, internal copying ("plagiarism"), joint composing at one word-processor, and the revising and editing of drafts.

Readers and writers from both inside and outside the organization participated in what I would describe as a consensual process of group identification to achieve as their goal a text that would meet both the common and conflicting needs of participants in the process. This motive for identification or consensus (usually mindful of self-image promoted by the ideals of corporate culture) generated a degree of good will that allowed participants to give and take relatively freely in the construction of their text. In contrast, at the post-product stage writers have given up ownership of their texts and have ceased revising and editing so that their texts are subject to any number of unpredictable influences over which they have little or no control. However, at the pre-product stage of the report processes I examined, readers and writers are actively participating in the construction of their texts. This pre-product freedom stands in relative contrast to the post-product construction of textual meaning which is more closed to reader input and is more susceptible to a divisive reading in which group differences, instead of group identification, predominate.

I have selected three examples of such cohesive-seeking behaviour in the processes I studied: an internal audit report by an accounting firm, a submission by a humanitarian organization to the B.C. Royal Commission on Education, and a problem/solution report by the city stock exchange. 
At the accounting firm, I studied the development of an interim audit repon for a hospital, a long-standing client of the firm. The two chartered accountants with primary responsibility for doing the audit indicated that the purpose of the report was not only to provide information, evaluate and advise, but also to create good will and maintain this valued client. (It had been rumoured the client was unhappy and looking for another accounting firm to do its auditing.) The junior CA was thus instructed by the senior CA to delete a major, unfinished component to facilitate early submission. It was considered politic to avoid delay in order to confirm interest in the client with some speedy initial feedback. This particular change was primarily the result of indirect, networking feedback from the readers of the report.

In addition, through direct involvement, certain hospital personnel also influenced how the report developed. The junior CA spent nine days collecting data at the client's premises. He interacted with six different client members, including the Chief Accountant, the Director and the Assistant Director of Finance. As a result of this consultation and subsequent telephone calls, the junior CA decided to forego "bad-news" strategies since any such news had already been conveyed during the composing process. Moreover, the next-to-final draft was sent to the Director of Finance whose comments were incorporated into the final copy before presentation to the hospital's Board. For readers who were already privy to the report's contents, its purpose as a product was thus primarily record-keeping. For "new" readers on the Board, the report was important for both its informative and persuasive effects; for pre-product readers such effects were largely immaterial.

The Royal Commission proposal was developed by an international humanitarian society. Initially the organization had requested and received a number of Commission documents with guidelines for submissions. Then, as the project got underway, the Assistant to the Commissioner met informally with the coordinators to discuss proposal strategies. Although he didn't give them much hope, he indicated there could be "limited returns"-some measure of positive response from the Commission was possible. Subsequently, the coordinators discussed the situation and decided to persevere since any chance at success would make a humanitarian effort 
worthwhile. Had the Assistant completely discouraged their project, they would not have gone ahead. His readerly intervention affected them otherwise.

The Assistant had also given them advice on what to emphasize in their proposal to help make it match the Commission's priorities. As a result, they each revised their drafts to reflect these goals; for example, they argued why an external institution rather than an internal department should provide their proposed programs, recommended their programs be delivered extracurricularly instead of integrated with existing school curricula, and provided additional statistical data as support. In the role of a real reader, the Assistant thus provided input that had a major effect on how the report evolved.

A fourth, external reader/writer was also in on the collaborative process of developing this report. The society had hired a professional writer to provide a final revision. He pulled together commonalities in the coordinator's drafts, and composed the Executive Summary.

At the third organization, a stock exchange, I studied the writing process involved in developing a problem-solution report that was geared to address a serious procedures problem. Apparently a number of problems had arisen on a particular seasonal holiday. As a result, this exchange found itself closed on a day when the TSE was open. This was an unprecedented and disturbing occurrence. The object of the report was to propose ways of preventing similar problems the following year.

Problem-solving took place primarily at meetings. Three coordinators . from the computer systems arm of data-processing were responsible for actually composing the report. They attended all of these meetings where they presented research and drafts to other staff, who would ultimately be responsible for implementing their recommendations. These readers participated thoroughly in the development of the report. Other information was acquired through telephone conversations with staff at the TSE, and initial data was secured by canvassing the brokerage community who were a major impetus behind the report. Subsequent to the meetings there was also input and revising by all managers and supervisors in the data-processing 
department. As a result, before the report became a "product" many of its targetted readers had already expressed and negotiated their needs through its development.

What I have described here are some of the dynamics of the writing process that are directly attributable to real readers and/or writers in their collaborative efforts to produce a report that will meet their respective concerns. I have focused on the audience or reader's role at this pre-product stage because I think, as instructors, we don't consider the active input of real readers: we tend instead to depict a passive, post-product reader whose needs the writer must guess at, intuit, or "imagine," and who only comes alive when the process is complete or "closed" and out of the writer's hands. The report-writing processes I have described here challenge this characterization of audience.

A report begins as a consequence of a situation and continues to influence events after its submission: it is embedded in a human context. As proponents of the sociological school insist, effective pedagogy should incorporate consideration of this social context or discourse community. Faigley points out that the social group to which the writer belongs defines, organizes and maintains itself through strategic acts of communication (235). In the process of constructing a text the writer must utilize or invoke the rhetorical strategies of what Kenneth Burke calls "identification" and "courtship." The text is composed to reflect and constitute the common interests of a particular discourse community. It is the reader's participation that increases the writer's chances of succeeding in this endeavour.

Both cognitive psychologists and compositionists support contextualized learning. In his article, "The Relation of the Whole to the Part in Interpretation Theory and in the Composing Process (in The Territory of Lanquage 1986), James Kinneavy concludes that the "catalytic agent" that "enables the student to see the relevance of skill exercises to actual writing situations" is the "critical level" of situational context (292): "Only in the dialect with the situational context do the word, then the sentence, the section, and even the text encounter the real tentativeness, changing relationships, relativity, and reciprocal interdependence which are determinative" (312). Kinneavy concludes that "when we can pose real 
communication situations there is the highest likelihood of transfer of skills. Otherwise the situational context has to be simulated. And the further away the level is from the situational context, the less likely is there to be the motivation to transfer" (312).

Contextualizing writing tasks in the classroom is not easy. The classroom itself is a mediating barrier to learning in real-world contexts. And the face-to-face, real one-on-one reader/writer situation is a relatively informal speech exchange system that resists evaluation. Instructors also face the problem of formulating and assessing their students' knowledge of context or culture, since such knowledge is often tacit (Polanyi 1966) and "not given" (Bruner 1973). How does one identify, teach, and demonstrate tacit knowledge?

Perhaps what is paramount from a pedagogical point of view is the problem of how to generate or provide appropriate contex ts for triggering the kind of communicative competence that effective writing entails. Our writing pedagogy tends to short-change our students: beyond teaching decontextualized invention strategies, like those popularized through the cognitive process approach, we have not helped our students develop the ability to "discover the available means of persuasion" (as Aristotle counsels). Our methods should embrace the possibilities of real reader/writer interaction by including opportunities for cooperative teamwork, collaborative problem-solving, and negotiation. Many students, especially non-mainstream students who are now the majority in many colleges, need instruction in interviewing and meeting skills, and in business and office protocol. My study suggests that it is a mistake to isolate the skills involved by teaching them in different courses; for example, oral communication and public speaking as one course, interpersonal skills as another, and writing as a third. Integrating these in one course is admittedly a challenge--and for some an administrative nightmare--but it would enhance cognitive function and transfer across skills and disciplines.

Teaching writing as part of a social process also means beginning before what is commonly understood as the pre-writing situation, so that students are called upon to construct the writing scenario in collaboration with others, instead of, for example, to read the given summary of a 
scenario in a textbook of cases. Some instructors of practical and business writing have already adopted "real-world" pedagogies; some are based on simulating the workplace or corporation in the classroom; others provide writing opportunities outside the classroom for real readers and clients in business and industry.

For those of us for whom such changes are prohibitive, and who must deal with the constraints of the classroom, collaborative work is still a reliable method for increasing the number of real readers. Of the configurations that collaboration took in the writing processes I studied, the most common by far was the novice/expert whereby a junior member was guided by a senior member of an organization who read and commented on elements of the process. Setting up this configuration within groups could increase the effectiveness of group work, which many instructors know can be quite problematic. Classroom instructors can also fulfill the role of expert; however the challenge for instructors (and for expert students as well) is to gain a measure of the credibility that is automatically accorded senior members of the workplace.

In addition to these possibilities, I think many educational institutions could begin to teach writing-in-the-field. Since many students carry out practicums in their chosen field, writing instructors could also participate in their students' field experience, adapting instruction to help students deal with both the contextual and textual problems involved in performing writing tasks on the job. In courses where students are writing for publication in particular, the writing instructor could be out of her typical classroom role and elsewhere on campus or in the community. These are not new suggestions, but need to be recast as focal in our efforts to realize reader participation in the construction of workplace documents.

In conclusion, two points relevant to this study should be made: one a caveat and the other speculative. I should first note that the non-statistical method of research I adopted is never conclusive, and that new and different contexts in each of these six organizations will mean shifts in their corporate patterns and changes in their reporting process.

Second, I should like to speculate on possible extrapolations of readerresponse theory as applied to the role of real readers in the writing process. 
The concept of what Umberto Eco describes as "more or less closed or open" texts suggests possible, further implications. In The Role of the Reader (1979) Eco explains that both open and closed texts request the cooperation of the reader, but a more or less open text validates "the widest possible range of interpretive proposals" (33). The open text offers multiple probabilities (Eco 34), whereas in a less open text the "sender offers his addressee continual occasions for forecasting, but at each further step he reasserts, ... the rights of his own text, saying without ambiguity what has to be taken as 'true'" (Eco 34).

As I have already noted, at the process or pre-product stage readers and writers participate with a greater degree of openness than they do at the postproduct stage. That is, reader/writer interaction and collaboration are rich and frequent in the development of an "open text," and affect how the text is constructed and comes to mean something for these participants. At the post-product stage, however, the text presents more non-negotiable constraints on how the reader constructs its meaning, and in fact assumes a different kind of audience. The more open a text is, the more intertextual play and role-switching between readers and writers. A relatively closed text reduces the range of choices offered to the reader in the constructing of meaning. The distinction between these two types of text supports and illuminates recent research in non-academic composing processes, especially that of Odell, Faigley, and Pare, who advocate pedagogies that incorporate elements of the social context of writing.

I have focused on the collaborative participation of real readers in the construction of a text that is relatively open during the process of composing. And I have contrasted this text-in-process to the relatively closed, post-product text. I have not explored the emergence of what one might name the non-product text: the text that exists only on-line and is therefore accessible to any number of reader-writers. This text, postulated by computer enthusiasts, is soft and perpetually changing as readers construct and re-construct meaning. This is a text that defers linguistic and interpretive closure indefinitely. With such texts and constraints that would be given in a less open text, say the text negotiated by real readers in the report-writing processes I have described here, are even less fixed. From one point of view, such texts invite enriched reader-response. What this might 
mean for pedagogy is unclear, but the absence of interpersonal contact does suggest one possibility, that the entire situational context could become tacit, potentially excluding those students and writers who have had no access to organizational culture. On the other hand, increased reader participation might improve motivation and accelerate learning.

This development is still only experimental and may in fact be illusory. But the composing process it suggests is a logical extension of the application of reader-response theory. And this framework can help to explain how readers collaborate with writers in the interests of producing a document that they can all live with.

\section{BIBLIOGRAPHY}

Bruner, Jerome. Beyond the Information Given. Ed. J.M. Anglin. New York: W.W. Norton and Company, Inc., 1973.

Burke, Kenneth. A Rhetoric of Motives. Berkley: University of California Press, 1950.

Eco, Umberto. The Role of the Reader. Bloomington, Indiana University Press, 1979.

Faigley, Lester. "Nonacademic Writing: The Social Perspective." Writing in Nonacademic Settings. Eds: Loe Odell and Dixie Goswami. New York: The Guilford Press, 1985, 231-248.

Kinneavy, James $L$. "The Relation of the Whole to the Part in Interpretation Theory and in the Composing Process." The Territory of Language. Ed. Donald A. McQuade. Carbondale: Southern Illinois University Press, 1986.

Lannon, John M. Technical Writing. Boston: Little, Brown and Company, 1985.

McMahan, Elizabeth and S. Day. The Writer's Rhetoric and Handbook. New York: McGraw-Hill Book Company, 1984. 
Odell, Lee. "Beyond the Text: Relations between Writing and Social Context." Writing in Nonacademic Settings. Eds. Lee Odell and Dixie Goswami. New York: The Guilford Press, 1985, 249-280.

Oliu, W.E., C.T. Brusaw, and G.J. Alred. Writing That Works. New York: St. Martin's Press, 1984.

Pare, Anthony. Unpublished presentation at CCTE, Vancouver, May 1989.

Polanyi, Michael. The Tacit Dimension. New York: Doubleday and Company, Inc., 1966. 